\title{
La necedad de ser
}

\section{Mónica Daniela Albarrán-Bernal}

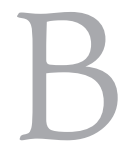

ernardo Bucio sintió en el fondo de sus entrañas lo que él llama: la necesidad de ser. Esa sensación le escocía el cuerpo como fuertes y ensalivadas lenguas de fuego. No siempre sucedía, a veces pasaba días, semanas, meses, incluso años sin sentirla. Pero esta vez le llegó. Se sentó en su escritorio y comenzó a escribir.

Lo primero que hacía era nombrar a sus personajes; según él, de esa manera comenzaban a nacer. El nombre. De pronto, tuvo la dificultad de nombrar a su personaje. Se puso a pensar. ¿Sería hombre o mujer?, o mejor un niño, no, no, un niño sería imposible. Mejor una mujer. La llamaré Lulú. Lulú como "Las edades de Lulú». No, es que eso sería absurdo, ya está esa Lulú y no me interesa el tema de las inocencias.

Siempre le había funcionado esa técnica, los nombres van primero. Pero esta vez se le escapaba de las manos, de nuevo no sabía cómo nombrarlos. Decidi empezar con el principal, porque siempre debe haber un principal ino? Miriam. ¿Cómo será Miriam? Gorda, flaca, blanca, morena. Bernardo decidió que el aspecto físico se lo dejaría al lector.

Ahora recordó que desde hacía cinco años no publicaba nada, ni en revistas ni siquiera en un periódico. Se había quedado mudo y ni siquiera se molestó en intentar sacar de sus entrañas lo que él llamaba con tanto ímpetu la necesidad de ser. Ahora que lo pienso, debería llamarle necedad, porque en eso me he convertido, en un necio, en un terco, ya ni puedo nombrar a mis personajes. Luego, volvió a pensar en Miriam. 
Bucio tomó un sorbo de su café mientras, con impaciencia, Miriam esperaba la llamada que iba a decidir su futuro. La llamada llegaría, estaba segura de eso. Pero la espera es una tortura, es peor, incluso, que una negación. La espera, en ese momento, ella la equiparaba con la muerte. ¿De quién será esa llamada? De su esposo, de una relación amorosa, de un inesperado trabajo. Me gusta lo del inesperado trabajo.

El teléfono cimbró como un temblor en su mesita de centro. Las manos de Miriam comenzaron a sudar, un frío le recorrió la espalda. Dejó que el teléfono diera dos timbrazos, temía que pensaran que estaba desesperada o que sólo esperaba esa llamada. Levantó el auricular. ¿Será una voz de mujer? ¿Le ofrecerán el trabajo de sus sueños? Bucio siguió escribiendo para que no se le fuera la idea.

¿Diga? Doctora Miriam, le llamo de la agencia Shunia Shop, hace unos días tuve una entrevista con usted para lo del puesto Senior en Marketing, ¿lo recuerda? Oh sí, claro que lo recuerdo, dígame. ¿No se estará oyendo falso? Intervino Bucio. No, mejor sigo, siempre hay que seguir hasta las últimas consecuencias. Hemos revisado con mucho cuidado a todos los postulantes y me gustaría tener una segunda entrevista con usted, claro, si es que sigue interesada. Claro que sigo interesada, pero antes de realizar esa segunda entrevista me gustaría saber claramente cuáles son las prestaciones que su empresa me ofrece, como verá cuento con mucha experiencia y tengo otras propuestas de trabajo, quisiera irme con la que más me convenga. Miriam no pensó en lo que acababa de decir, la verdad es que llevaba bastante tiempo sin lograr encontrar trabajo y gran parte de su hoja de vida era mentira, sobre todo en cuanto a la experiencia laboral, que era escasa, si bien su preparación académica era de excelencia.

¿Sí estará bien una llamada de trabajo? ¿Por qué no de amor? iUna llamada de amor!, eso siempre funciona. Bucio guardó el primer párrafo en una aplicación tipo Post it que tenía en el escritorio de su ordenador. Una llamada de amor o de desamor. Veamos. Se levantó de su asiento a tomar un poco de agua, la emoción de la llamada le dejó la boca seca.

Miriam preparaba la maleta porque esta tarde partiría con su esposo a la casa de sus padres. ¿Cómo se llamará el esposo? Serían un par de semanas, su padre no se encontraba bien y... ¿Cómo diablos le pongo? Bill (suena a extranjero, pero en mi cabeza y en la cabeza de Miriam tiene cara de Bill), ella y su padre se llevaban de maravilla. Mientras esperaba la llamada de Bill para verse en el aeropuerto, decidió echar en la maleta, aparte de la ropa, un balance de su vida. Todo era perfecto, tenía una carrera exitosa como fisioterapeuta y un marido al que amaba casi con locura. No habían tenido hijos porque no eran de esas parejas. Les gustaba disfrutarse el uno al otro. Sí, era feliz.

Estaba saboreando su felicidad cuando sonó la esperada llamada, ¿deben ser felices por siempre?, se preguntó Bucio, y de ser así, ¿cuál sería el fin fatal?, la muerte del 
padre de Miriam, pensó, sería un buen pretexto para unir más a Miriam y a Bill. Era Bill al otro lado de la línea. Miriam escuchó la respiración agitada de su esposo. Bill ¿está todo bien? Miriam, no puedo. No puedo ir contigo a casa de tus padres. ¿De qué hablas, Bill?, ya tengo todo listo. Espero que hayas comprado a tiempo los boletos de avión. Si no los compraste, cielo, tendremos que manejar y sabes que son varias horas. Miriam, tienes que entender que no puedo, estoy hablando en serio. Conocí a alguien más. ¿Cómo que a alguien más?, estás loco, esto es una broma, ¿verdad? Ya no soporto esta situación, no puedo mentirte más. Bucio ahora sí que estaba disfrutando la historia. Te amo, te amaba, no sé qué pasó, fueron los años, fue que me enamoré de otra persona, lo siento. Silencio. El corazón de Miriam se le congeló junto con la voz. No podía responder. Cómo reacciona una mujer ante una confesión así, con dolor, con enojo, con furia, Bucio comprendió que no sabía cómo respondería nadie ante tal situación. Al menos no en ese momento.

Dejó por ahora esa narración inconclusa ipor qué no puedo terminar ninguna historia?, se preguntó Bucio con un profundo dolor. Seguiré con el trabajo de Miriam. Releyó el inicio del relato y se dio cuenta de que no sabía cómo seguirlo, pero lo intentaría. Ok, veamos. Entiendo, Dra., y me parece excelente que usted se tome un tiempo para reflexionar sobre tomar esta gran oportunidad que le ofrecemos. Además del insuperable sueldo propuesto, también podrá hacer muchos viajes de negocios. Como sabe, nuestra empresa, aunque radica en Silicon Valley, tiene varias sedes en distintos lados del país y del mundo. Canadá, Inglaterra, España, Singapur y China, sólo por mencionar algunos. Aparte de eso, como sabemos que usted radica en México, estamos dispuestos a ayudarla a conseguir un crédito con alguna constructora de su preferencia para que no tenga problemas de vivienda y venga aquí a vivir con su esposo y su familia, si así lo deciden. Como verá, es una gran opción. Miriam lo pensó unos segundos y accedió a la segunda entrevista con la certeza de que pasara lo que pasara, ella aceptaría. Sabía que algo así no se le volvería a presentar en la vida.

De nuevo, Bucio comenzó a dudar. ¿Qué pasará con esta Miriam? De pronto esa historia se le antojaba demasiado sosa, incluso irreal, era mejor, tal vez, que todo sucediera por amor. Miram siguió en silencio unos segundos. Bill comenzó a angustiarse por su silencio, que al fin rompió. Tienes que venir. Por favor, ven. Esto no puede ser, Bill. Tú y yo nos amamos, nos hemos amado desde que íbamos en la universidad, desde hace casi veinte años, no puedes hacerme esto, hemos pasado una vida juntos, vivimos juntos, tenemos una casa, amigos, compartimos todo. No puede ser, no puedo creer que me estés dejando. ¿Quién es ella? Es que no lo entiendes, Miriam. No, no, no puede ser, no me comprendes. Te amo, o no sé si te amo. Perdóname. No me da la gana perdonarte, por favor, ven, tienes que venir ahora. Podemos arreglarlo, entiendo que te hayas enredado con alguna jovenzuela, lo comprendo bien. No, es que te juro, Miriam, que no hay tiempo, no tengo tiempo. Lo que hice 
es terrible. De qué hablas Bill, por Dios, todas las parejas tienen sus amoríos, cielo, te perdono, pero por favor, ven. Es que no comprendes, Miriam. No puedo irme, porque a la persona con la que me iré le queda poco tiempo. ¿Cómo que poco tiempo? Está enferma ¿Me estás pidiendo acaso una especie de licencia, un año sabático, nos separamos en lo que se muere tu amante? Dime quién es, por favor, ila conozco, acaso? ¿Es amiga nuestra, es alguien de tu trabajo? Por favor, habla de una vez. Sí, es alguien que conoces bien. ¿Entonces dime inmediatamente quién es ella? Es que no es ella, es él. De pronto Miriam sintió como se le caía el mundo a pedazos, años frente a sus ojos y no lo había visto. Se sintió asqueada, ultrajada. Enferma. ¿Su padre? Colgó.

Se sentó en su sofá, el mismo que su padre le había regalado cuando se casaron, varias retapizadas a lo largo de los años. No supo qué hacer. Bucio tampoco sabía qué más hacer, qué podía hacer Miriam al respecto, sintió que él era el monstruo que había creado a Bill y al padre de Miriam y quiso remediarlo. Me siento tan cansado, pero quiero terminar con la historia de Miriam. A ver, Miriam, ¿qué vas a hacer aho$\mathrm{ra}$ ? A veces se ponía a hablar con sus personajes, las pocas amistades que tenía le habían orillado a eso. Miriam lo decidió sola. Sintió un impulso verdadero, de esos que se sienten una vez en la vida, en los momentos extremos. Caminó alrededor de su casa, vio todo, toco todo con la mirada por última vez. Bucio tomó las manos de Miriam y le dio una botellita. Toma, Miriam, no sufras. Y perdóname. Miriam abrió la botellita y obedientemente cerró los ojos, la bebió. Se tumbó en el sofá y dejó de sufrir. Pero Bucio no, porque ahora se sentía culpable y terriblemente deprimido. Quería llevar a otro lado a Miriam. Siguió con la otra historia.

Miriam fue a la segunda entrevista, la recibieron con mucha amabilidad e interés, le gustó eso. En la entrevista le dijeron que era la oportunidad de su vida, y aunque ella lo sabía, aun quería que aumentaran su oferta. Lo hicieron, a su sueldo inicial le añadieron varios dólares y finalmente aceptó. Estaba tan contenta que no cabía en su cuerpo del gozo. Se despidió de todos, ya que el lunes próximo comenzaría a trabajar con ellos. Salió del gran edificio de Shunia Shop. Le estaba mandando un mensaje a su madre, ella tendría que ser la primera persona en saberlo. No volteó a su derecha porque de pronto se sintió invencible. Bucio se preguntó por qué tendría que ser tan fatalista todo lo que escribe, ¿desde cuando se volvió un asesino tan devoto? Sólo se escuchó un grito en la acera y el derrapar del auto. Miriam cayó al suelo, en su celular logró escribir: «Mamá, tengo una gran noticia». No logró enviarlo. Miriam murió al instante. La policía arribó al lugar, el auto no se dio a la fuga. Era un hombre corpulento de unos cuarenta y muchos años. Sus ojos estaban llenos de lágrimas. El policía le preguntó su nombre. Bernardo Bucio. Años: 48. Ocupación: escritor. 


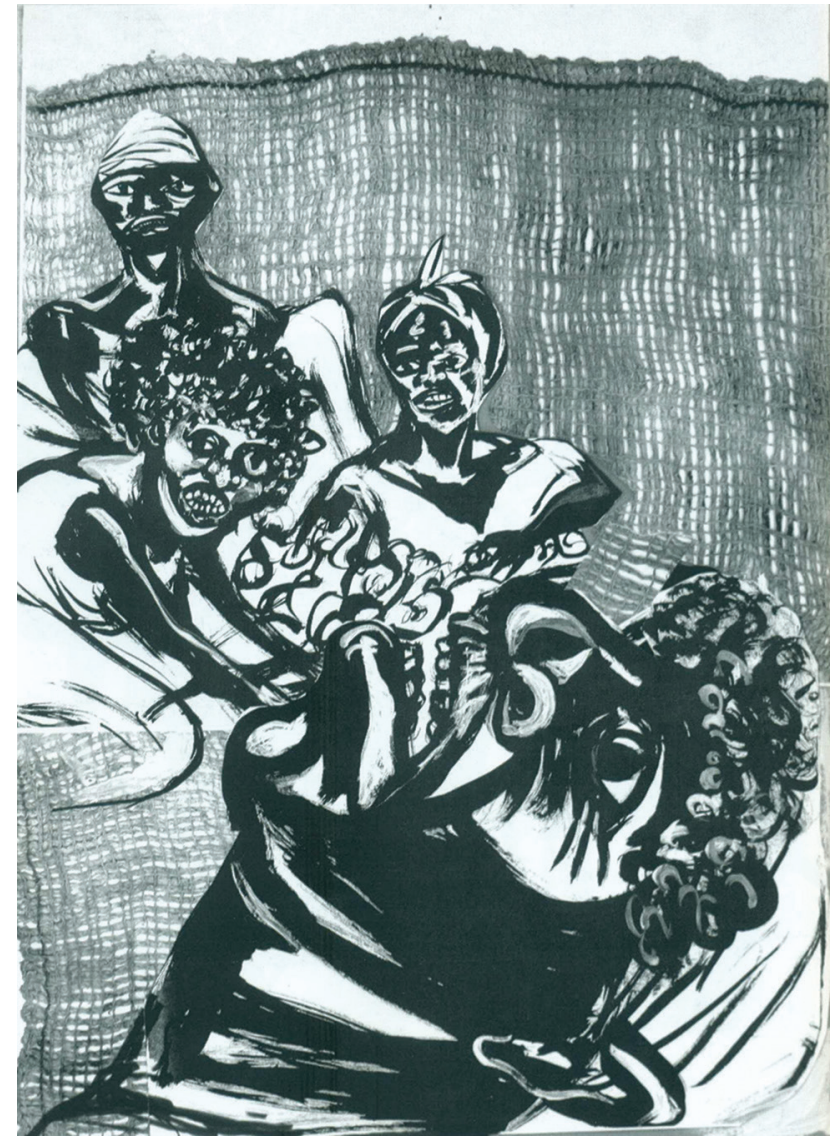

El matadero, Edhasa (2011). Tinta sobre papel y collage: Marcia Schvartz. Prohibida su reproducción en obras derivadas.

Mónica Daniela Albarrán-Bernal (Toluca, Estado de México, 1994). Es Licenciada en Letras Latinoamericanas por la Universidad Autónoma del Estado de México (UAEM), México. Ha publicado en Monolito, Grafógrafxs, Castálida y Viceversa Noticias. Su obra ha sido incluida en la Antología de poetas jóvenes del Valle de Toluca (Literatelia). 